\title{
COMPARISON OF DOUBLE AND SINGLE BONDED REPAIRS TO SYMMETRIC COMPOSITE STRUCTURES: A NUMERICAL ANALYSIS
}

\author{
B. Bachir Bouiadjra, M. Belhouari, B. Serier and D. Ouinas \\ Department of Mechanical Engineering, University of Sidi Bel Abbes, BP 89, Cité Ben M'hidi, Sidi Bel Abbes 22000, \\ Algeria
}

\begin{abstract}
Owing to the importance of crack patching in fracture mechanics analysis, the aim of this study is to analyse numerically by the finite element method the advantage of the use of the bonded symmetric composite pach for repairing crack in metallic sheet in pure mode I. The obtained results show that there is a considerable reduction of the asymptotic value of the stress intensity factor at the crack tip in the case of the use of the double symmetric patch compared with the single patch. In addition the gain of the composite thickness obtained by the double patch is also considerable in both mode I.
\end{abstract}

\section{INTRODUCTION}

The use of externally bonded composite patches for repairing crack and defects in aircraft structures knows a large success these last years, what accelerated the researches in this domain. The bonded composite repair carries a part of the loads acting at the crack tip throughout the adhesive. The stress intensity factor is then reduced by the presnce of the patch. Several authors showed that the mode I stress intensity factor of repaired crack, exhibits an asymptotic behaviour as the crack length increases [1-6]. The patch performance, depends essentially on the patch and the adhesive properties (shear modulus and thickness). Bachir et al [7] affirmed that the adhesive properties must be optimized in order to allow the transmission of the stresses toward the patch and to avoid the adhesive failure. Concerning the mechanical properties of the patchit is known that only the boron / epoxy and the graphite / epoxy are used because of their excellent load transfer characteristics [8]. One can conclude that the improvement of the patch performances by the assessment of the properties of the composite and the adhesive prove to be more difficult and expensive. The unique parameter that remains is the patch thickness. Bachir et al [7] slow that for a single patch repair the increase of the patch thickness about $50 \%$ reduces the stress intensity factors at the same order and they confirmed that for a better distribution of the stresses, it is preferable to use a multiple layers of bonded composite patch. One of means that can strengthen this ideas is the use of the double sided symmetric patch. Many authos shown the advantage of the double-sided symmetric patches experimentally and numerically, among them we can quote. Ting et al. [1], Turaga and Ripudaman [9], Chen and Yang [10], Megueni et al [11]. All these authors observe that the double-sided symmetric patch reduces more the stress intensity at the crack tip. In addition, it annuls the bending effect due to the eccentricity of the patch. This study has been led in the aim to achieve an advanced in this way using the Finite element method. First, one compares the values of the stress intensity factors of repaired cracks with single and double patches in pure mode I, then one determines the gain of the thickness eventually obtained by the use of the double symmetric patch. This gain can give us an approximate evaluation on the reduction of the cost of the repair that can generate the use of the double symmetric patch. 


\section{GEOMETRICAL MODEL}

The basic geometry of the cracked structure considered in this study is shown in figure 1 . Consider a thin elastic aluminium plate (height $\mathrm{H}_{\mathrm{p}}=254 \mathrm{~mm}$, width $\mathrm{W}_{\mathrm{p}}=254 \mathrm{~mm}$ and thickness $\mathrm{e}_{\mathrm{p}}$ $=5 \mathrm{~mm}$ ), with a central crack of length $2 \mathrm{a}$ repaired with boron- epoxy composite patch bonded with FM 73 adhesive having thickness $e_{a}=0,15 \mathrm{~mm}$. The width and the height of the patch are $\mathrm{W}_{\mathrm{r}} / 2=65 \mathrm{~mm}$ and $\mathrm{H}_{\mathrm{r}}=75 \mathrm{~mm}$, respectively. The patch thickness for a double patch is half of that used for a single patch (figure 1). The plate is subjected to a remote uniaxial tensile load of $\square=70 \mathrm{Mpa}$, the plane stress conditions are assumed. Since the geometry and loading is symmetric, only one half of the structure needs to be analysed. The material properties of the plate, patch and adhesive are:

Plate (aluminium): Young modulus Ep $=72 \mathrm{GPa}$, Poissson ratio $\square_{\mathrm{p}}=0.33$.

Patch (boron - epoxy): Young modulus $\mathrm{E}_{\mathrm{r} 1}=210 \mathrm{GPa}, \mathrm{E}_{\mathrm{r} 2}=\mathrm{E}_{\mathrm{r} 3}=19.6 \mathrm{GPa}$, shear modulus $\mathrm{G}_{\mathrm{r}}=$ $5.460 \mathrm{GPa}$, and Poisson's ratios $\square_{\mathrm{r} 1}=0.3, \square_{\mathrm{r} 2}=\square_{\mathrm{r} 3}=0.2$

Adhesive (FM 73): Shear modulus $\mathrm{G}_{\mathrm{a}}=0.42 \mathrm{GPa}$

Finite element analysis of the configurations of figure 1 is done, using the finite element code Franc2D/L developed at Kansas University [12]. The global structure (plate and patch) is meshed using standard eight nodded-isoparametric elements with quadratic shape fundions. These elements perform well for elastic analysis and have the advantage that the stress singularity at the crack tip can be incorporated in the solution by moving the eight nodes to the quarterpoint locations [13]. Figure 2 shows the finite elemert modeling for the plate, and the patch. The stress intensity factor is calculated using modified crack closure method.
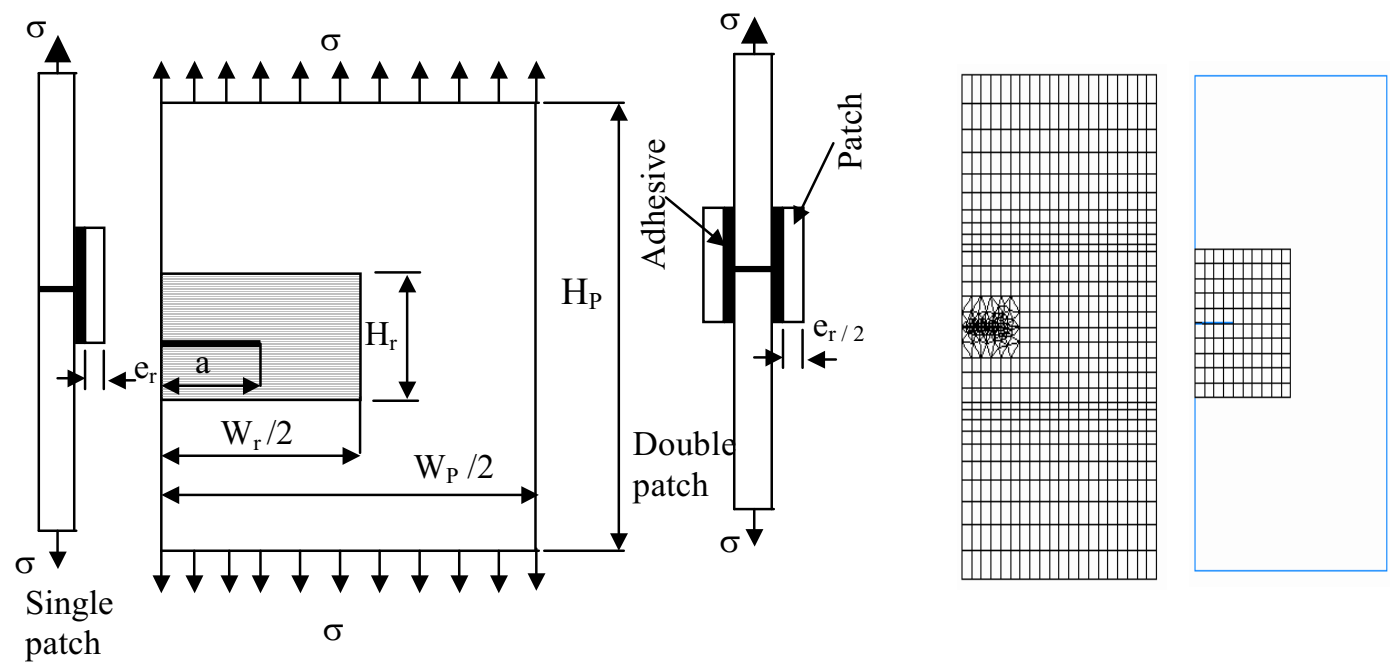

Figure 1: Geometrical model of the half of the patched structure for the pure mode I.
Figure 2: Typical mesh model of the plate, and patch in pure mode I. 


\section{RESULTS AND DISCUSSIONS}

3.1 Comparison between single and double patched crack

Figure 3 presents the variation of the stress intensity factor $K_{\mathrm{f}}$ according to the crack length for single and symmetric double patch for thickness $\mathrm{e}=5 \mathrm{~mm}$. It is firstly noted that the asymptotic behaviour is visible for the two cases and there is a reduction of the asymptotic value about $10 \%$ by the use of double symmetric patch, it means that the fatigue life of the structure can be improved considerably. This tendency is in agreement with the analysis of Klug et al [14] whom showed that the use of a double patch increase twice as much the fatigue life of the structure compared with the single patch. It can also be see in figure 3 that for a weak value of the crack length there is no difference in the stress intensity factor between the case of single and double symmetric patch. This is due to the fact that the stress intensity at the crack tip for weak values of the thickness is not sufficient to highlight the advantages of the double transfer of stresses.

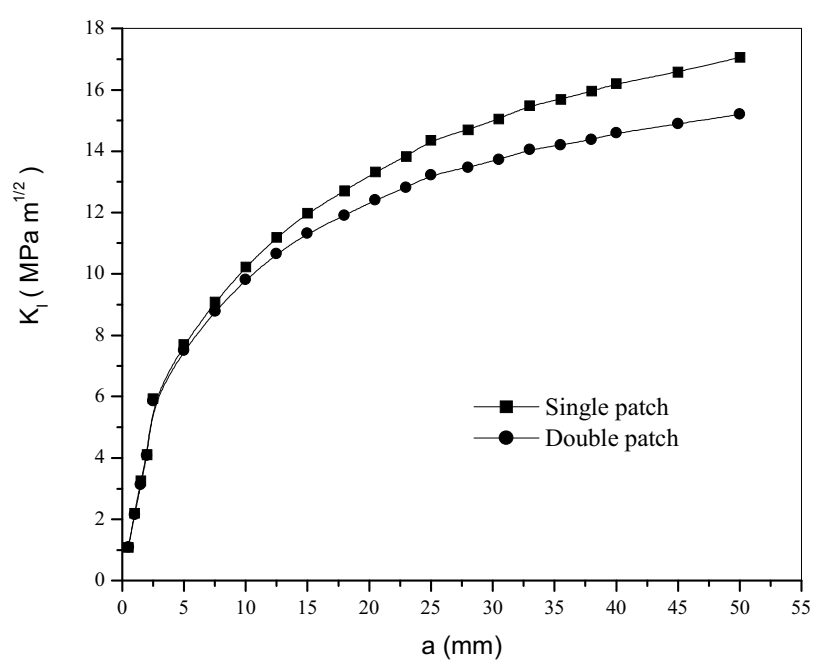

Figure 3: Comparison of the stress intensity factor between single and double patched cracks.

For a better illustration of the beneficial effect of the double symmetric patch it is plotted in figure 4 the variation of the asymptotic SIF according to the patch thickness for a single and double patch. For the two cases the SIF decreases asymptotically as thepatch thickness grows. It is then useless to increase the patch thickness indefinitely for reducing the stress intensity factor. An optimization of the patch thickness is recommended. Ting et al [1] andTuraga and Ripudaman [9] obtained this conclusion. It is noted that the difference of the stress intensity factor between a single and double symmetric patch is stabilized when the thickness e is greaten then $2 \mathrm{~mm}$. This tendency is confirmed by the figure 5 that illustrates the variation of the ratio $\mathrm{R}\left(\mathrm{R}=\mathrm{K}_{\infty}{ }^{\mathrm{s}} / \mathrm{K}_{\infty}{ }^{\mathrm{d}}\right.$, $\mathrm{K}_{\infty}{ }^{\mathrm{s}}$ and $\mathrm{K}_{\infty}{ }^{\mathrm{d}}$ are respectively the asymptotic value of the SIF for single and double patch), as a function of the patch thickness. It can be seen that the ratio $\mathrm{R}$ increases asymptotically when $\mathrm{e}$ increases. 


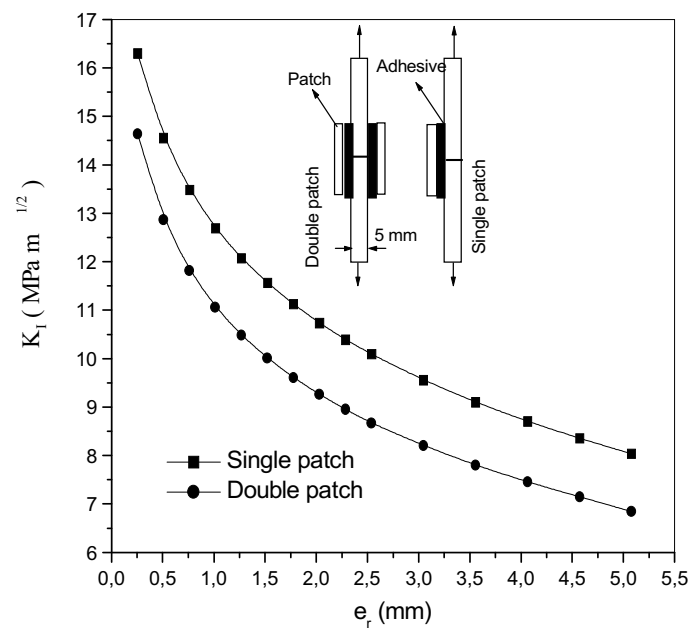

Figure 4: Effect of the patch thickness on the mode I stress intensity factor variation

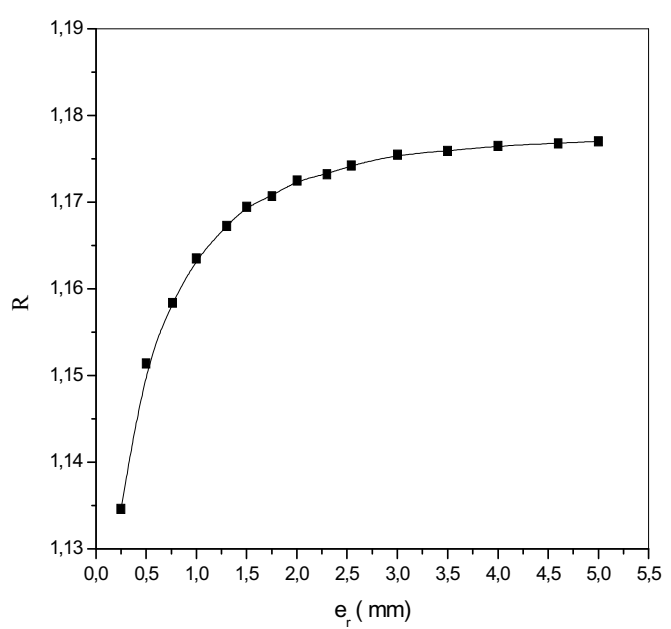

Figure 5: Variation of the ratio $\mathrm{R}$ according to the patch thickness.

Tables 1-4 present the gain of thickness eventually obtained by the use of the double symmetric patch. This gain is defined as the relative difference in percent between the thickness of double symmetric and single patch when the SIF is the same for the two cases. Tables 14 are established for different crack lengths. It can be noted that the gain may be considerable and it reaches about $46 \%$ for $\mathrm{a}=50 \mathrm{~mm}$, which permits us to confirm that while adding the gain obtained by the elimination of the bending effect, the total gain obtained by the use of thedouble patch can largely exceed $50 \%$. It can also be seen in table 1 that the gain decreases as the patch thickness increases. This is due to the fact that the transfer of the stress towards the patch is less important for high values of the patch thickness, then the difference of the transferred stresses between a single and double symmetric patch is less important.

\begin{tabular}{|c|c|c|c|c|}
\hline $\begin{array}{c}\mathrm{e}_{\mathrm{r}}(\mathrm{mm}) \\
\text { double patch }\end{array}$ & $\mathrm{K}_{\mathrm{I}}(\mathrm{Mpa} \sqrt{\mathrm{m}})$ & $\begin{array}{c}\mathrm{e}_{\mathrm{r}}(\mathrm{mm}) \\
\text { single patch }\end{array}$ & $\mathrm{K}_{\mathrm{I}}(\mathrm{Mpa} \sqrt{\mathrm{m}})$ & Gain \% \\
\hline 1 & 6,754 & 1,54 & 6,753 & 35,06 \\
\hline 2 & 6,196 & 2,92 & 6,196 & 31,51 \\
\hline 3 & 5,792 & 4,225 & 5,792 & 28,99 \\
\hline 4 & 5,476 & 5,45 & 5,475 & 26,61 \\
\hline 5 & 5,193 & 6,71 & 5,193 & 25,48 \\
\hline
\end{tabular}

Table 1: Evaluation of the gain in pure mode I for $\mathrm{a}=5 \mathrm{~mm}$. 


\begin{tabular}{|c|c|c|c|c|}
\hline $\begin{array}{l}\mathrm{e}_{\mathrm{r}}(\mathrm{mm}) \\
\text { double patch }\end{array}$ & $\mathrm{K}_{\mathrm{I}}(\mathrm{Mpa} \sqrt{\mathrm{m}})$ & $\begin{array}{c}\mathrm{e}_{\mathrm{r}}(\mathrm{mm}) \\
\text { single patch }\end{array}$ & $\mathrm{K}_{\mathrm{I}}(\mathrm{Mpa} \sqrt{\mathrm{m}})$ & Gain \% \\
\hline 1 & 8,445 & 1,63 & 8,444 & 38,65 \\
\hline 2 & 7,512 & 3,1 & 7,511 & 35,48 \\
\hline 3 & 6,872 & 4,52 & 6,871 & 33,63 \\
\hline 4 & 6,407 & 5,82 & 6,407 & 31,27 \\
\hline 5 & 6,009 & 7,2 & 6,005 & 30,56 \\
\hline
\end{tabular}

Table 2: Evaluation of the gain in pure mode I for $\mathrm{a}=10 \mathrm{~mm}$.

\begin{tabular}{|c|c|c|c|c|}
\hline $\begin{array}{c}\mathrm{e}_{\mathrm{r}}(\mathrm{mm}) \\
\text { double patch }\end{array}$ & $\mathrm{K}_{\mathrm{I}}(\mathrm{Mpa} \sqrt{\mathrm{m}})$ & $\begin{array}{c}\mathrm{e}_{\mathrm{r}}(\mathrm{mm}) \\
\text { single patch }\end{array}$ & $\mathrm{K}_{\mathrm{I}}(\mathrm{Mpa} \sqrt{\mathrm{m}})$ & Gain \% \\
\hline 1 & 10,48 & 1,75 & 10,48 & 43 \\
\hline 2 & 8,94 & 3,3 & 8,95 & 39,39 \\
\hline 3 & 8,021 & 4,8 & 8,021 & 37,5 \\
\hline 4 & 7,358 & 6,16 & 7,357 & 35,06 \\
\hline 5 & 6,839 & 7,52 & 6,839 & 33,51 \\
\hline
\end{tabular}

Table 3: Evaluation of the gain in pure mode I for $\mathrm{a}=25 \mathrm{~mm}$.

\begin{tabular}{|c|c|c|c|c|}
\hline $\begin{array}{c}\mathrm{e}_{\mathrm{r}}(\mathrm{mm}) \\
\text { double patch }\end{array}$ & $\mathrm{K}_{\mathrm{I}}(\mathrm{Mpa} \sqrt{\mathrm{m}})$ & $\begin{array}{c}\mathrm{e}_{\mathrm{r}}(\mathrm{mm}) \\
\text { single patch }\end{array}$ & $\mathrm{K}_{\mathrm{I}}(\mathrm{Mpa} \sqrt{\mathrm{m}})$ & Gain \% \\
\hline 1 & 11,74 & 1,85 & 11,75 & 45,95 \\
\hline 2 & 9,86 & 3,4798 & 9,87 & 42,53 \\
\hline 3 & 8,77 & 5,03 & 8,78 & 40,36 \\
\hline 4 & 8,06 & 6,452 & 8,06 & 38,00 \\
\hline 5 & 7,49 & 7,874 & 7,489 & 36,50 \\
\hline
\end{tabular}

Table 4: Evaluation of the gain in pure mode I for $\mathrm{a}=50 \mathrm{~mm}$.

\section{CONCLUSION}

In this study the finite element method has been used to analyse the advantage of the use of the boned symmetric composite patch for repairing crack. The obtained results allow us to deduce the following conclusions:

- The use of the double patch reduces appreciably the stress intensity factor compared to single patch. 
- The stress intensity factor decreases asymptotically according to the thickness $\delta$ the patch, the relative difference between the SIF of the double and single patch is almost constant.

- The ratio $\mathrm{R}$ increases asymptotically with the thickness of the patch. This ratio becomes independent of the thickness from a certain value. An optmisation of the patch thickness is thus recommended.

- The gain in thickness increases with the crack length and it decreases when the thickness of the patch increases. For small length this gain can exceed largely $50 \%$ at the asymptotic value of the SIF.

\section{REFERENCE}

[1] Ting T, Jones R, Chiu WK, Marshall IH and Greer JM. Composites repairs to rib stiffened panels. Composite Structures 1999; 47: 737-743.

[2] Callinan RJ, Sanderson S and Keeley D. Finite element analysis of an F111 lower wing skin fatigue crack repair, DSTO, Melbourne. DSTOTN-0067, 1997.

[3] Jones R and Chiu WK. Composite repairs to crack in metallic components. Composite Structures 1999; 44:17-29.

[4] Achour T , Bachir BB and Serier B. Numerical analysis of the performance of the borded composite patch in reducing stress concentration and repairing crack at notch. Computational material sciences 2003; 28: 41-48.

[5] Schubbe JJ and Mall S. Modeling of cracked thick metallic structure with bonded composite patch repair using three-layer technique. Composite Structures 1999; 45:185-193.

[6] Rose L.R.F. An application of the inclusion analogy for bonded reinforcements. International Journal of Solid and Structures 1981; 17: 827-38.

[7 ] Bachir BB, Belhouari M and Serier B. Computation of the stress intensity factors for patched cracks with bonded composite repairs in mode I and mixed mode. Composite Structures 2002; $56: 401-406$.

[8] Baker AA. Bonded composite repair for fatiguecracked primary aircraft structure. Composite Structures 1999; 74: 431-443.

[9] Turaga VRS and Ripudaman S. Modelling of patch repairs to a thin cracked sheet. Engineering Fracture Mechanics 1999; 62: 267-289.

[10] Chen WH and Yang SH. Estimation of stress intensity factors in partially patched cracked composite laminates by multiplayer hybrid-stress finite element method. Finite Elements in Analysis and Design 1995; 21: 21-44.

[11] Megueni A, Bachir BB and Boutabout B. Computation of the Stress Intensity Factor for patched crack with bonded composite repair in pur Mode II. Composite Structure 2003;59:415418.

[12] Swenson D and James M. FRANC2D / L: A crack propagation simulator for plane layered Structures. Version 1.4 User's guide, 1998.

[13] Henshel R.D and Shaw K.G, Crack tip finite elements are Umecessary, International Journal for Numerical Methods in Engineering 1975: 9:495-507.

[14] Klug J.C, Maley S and Sun CT Characterization of fatigue behavior of bonded composite repairs. J Aircraft 1999; 36 (6): 1016-22. 